\title{
O PROGRAMA ESCOLA LIVRE EM ALAGOAS, A CRISE DE ACUMULAÇÃO DO CAPITAL E O FORTALECIMENTO DA DIREITA POLÍTICA BRASILEIRA
}

\author{
Jorge Fernando Hermida ${ }^{1}$ \\ Jailton de Souza Lira²
}

\section{RESUMO}

Este artigo analisa o processo de aprovação da Lei n 7.800 , de 05 de maio de 2016 , que institui, no âmbito do Sistema Estadual de Ensino, o Programa Escola Livre em Alagoas. Segundo seus defensores, a lei procura atuar na defesa a "neutralidade" ideológica, política e religiosa dos professores e sua aprovação provocou intensos debates entre segmentos da sociedade civil, instituições educacionais e religiosas, movimentos sociais, educadores e estudantes. A questão norteadora que orientou a pesquisa foi a seguinte: quais circunstâncias econômicas, políticas e ideológicas motivaram a aprovação da lei 7.800/2016, que institui o Programa Escola Livre no Estado de Alagoas? Com base na interpretação marxista da história, o artigo utilizou como método o materialismo histórico e dialético. O artigo conclui que a aprovação da lei foi possível graças às peculiaridades culturais, econômicas e políiticas do estado de Alagoas, levando em conta a existência de fortes traços de prática coronelista e violência política, que convivem historicamente com um elevado índice de desigualdade social e concentração de riquezas. Outro aspecto importante diz respeito à tentativa de homogeneização dos sujeitos educacionais, negando as diferenças existentes no tecido social, além de monitorar o trabalho docente, esvaziando-o de conteúdos e de metodologias que promovam o espírito crítico dos alunos. Os conceitos de educação, igualdade, liberdade e política evocados no texto da lei, evidenciam que o mesmo foi elaborado a partir de concepções ideológicas e de democracia burguesas (idealistas). Essas concepções se confrontam com as contradições, pluralidade e diversidade (reais) que caracterizam a sociedade brasileira.

Palavras-chave: Políticas Educacionais. Programa Escola Livre. Gestão Escolar. Ideologia Neoliberal.

\footnotetext{
1 Doutorado em Educação pela Universidade Estadual de Campinas (UNICAMP). Docente do Programa de Pós-graduação em Educação (PPGE) e do Mestrado Profissional Gestão em Organizações Aprendentes (MPGOA), ambos da Universidade Federal da Paraíba (UFPB). E-mail: jorgefernandohermida@yahoo.com.br

${ }^{2}$ Doutorado em Educação pela Universidade Federal da Paraíba (UFPB). Professor Assistente I da Universidade Federal de Alagoas (UFAL). E-mail: jailtonsouzalira@gmail.com
} 


\title{
THE FREE SCHOOL PROGRAM IN ALAGOAS, THE CRISIS OF ACCUMULATION OF CAPITAL AND THE STRENGTHENING OF THE RIGHT BRAZILIAN POLITICS
}

\begin{abstract}
This article analyzes the approval process of Law 7.800, dated May 5, 2016, which establishes, within the scope of the State System of Education, the Free School Program in Alagoas. According to its proponents, the law seeks to defend the ideological, political and religious "neutrality" of teachers and its approval has provoked intense debates among segments of civil society, educational and religious institutions, social movements, educators and students. The guiding question that guided the research was: what economic, political and ideological circumstances motivated the approval of the law 7.800/2016, which establishes the Free School Program in the State of Alagoas? Based on the Marxist interpretation of history, the article used historical and dialectical materialism as its method. The article concludes that the approval of the law was made possible by the cultural, economic and political peculiarities of the state of Alagoas, taking into account the existence of strong coronelist practices and political violence, which coexist historically with a high index of social inequality and concentration of riches. Another important aspect concerns the attempt to homogenize educational subjects, denying the differences in the social fabric, in addition to monitoring the teaching work, emptying it of contents and methodologies that promote the students' critical spirit. The concepts of education, equality, freedom and politics evoked in the text of the law, show that it was elaborated from ideological conceptions and bourgeois (idealistic) conceptions. These conceptions are confronted with the contradictions, plurality and diversity (real) that characterize Brazilian society.
\end{abstract}

Keywords: Education Policies. Free School Program. School Management. Neoliberal Ideology.

\section{EL PROGRAMA ESCUELA LIBRE EN ALAGOAS, LA CRISIS DE ACUMULACIÓN DEL CAPITAL Y EL FORTALECIMIENTO DE LA DERECHA POLÍTICA BRASILEÑA}

\section{RESUMEN}

Este artículo analiza el proceso de aprobación de la Ley $N^{\circ} 7.800$, de 5 de mayo, 2016, que establece en el Sistema de Educación del Estado, el Programa Escuela Libre en Alagoas. Según sus defensores, la ley busca actuar en defensa de la "neutralidad" ideológica, política y religiosa de los profesores, y su aprobación provocó un intenso debate entre sectores de la sociedad civil, instituciones educativas y religiosas, movimientos sociales, educadores y estudiantes. La cuestión principal que guió la investigación fue la siguiente: ¿̇qué circunstancias económicas, políticas e ideológicas motivaron la aprobación de la Ley 7.800/2016, que establece el Programa Escuela Libre en el Estado de Alagoas? Basado en la interpretación marxista de la historia, el artículo utilizó como método el materialismo histórico y dialéctico. El artículo concluye que la aprobación de la ley fue posible 
gracias a las peculiaridades culturales, económicas y políticas del estado de Alagoas, teniendo en cuenta la existencia de rasgos fuertes de coronelismo y violencia política, que conviven históricamente con un alto índice de desigualdad social y de concentración de la riqueza. Otro aspecto importante se refiere al intento de homogeneización de los sujetos educativos, negando las diferencias en el tejido social, además de supervisar el trabajo docente, vaciándolo de contenidos y metodologías que promuevan el pensamiento crítico de los estudiantes. Los conceptos de educación, igualdad, libertad y política mencionados en el texto de la ley, muestran que el mismo fue elaborado a partir de concepciones ideológicas y de democracia burguesas (idealistas). Estos puntos de vista se enfrentan con las contradicciones, pluralidad y diversidad (reales) que caracterizan a la sociedad brasileña.

Palabras clave: Políticas educacionales. Programa Escuela Libre. Gestión Escolar. Ideología Neoliberal.

\section{INTRODUÇÃO}

Em 2016, uma lei aprovada na Assembleia Legislativa do Estado de Alagoas repercutiu nos meios de comunicação e provocou intensos debates entre segmentos da sociedade civil, instituições educacionais e religiosas, movimentos sociais, educadores e estudantes de todo o país: trata-se da Lei $n^{\circ}$ 7.800, de 05 de maio de 2016, que segundo sua ementa "Institui, no âmbito do Sistema Estadual de Ensino, o Programa Escola Livre"3. A Lei 7.800/2016, de autoria do deputado estadual Ricardo Nezinho (Partido do Movimento Democrático Brasileiro - PMDB), passou a ser popularmente denominada como Lei da Escola Livre e foi aprovada pela maioria absoluta dos parlamentares daquela instituição4.

Apelidada pela comunidade educacional de "lei da mordaça", a lei fere os princípios sobre os quais está alicerçada a institucionalidade democrática brasileira e interfere decisivamente na construção da reflexão crítica e no processo de ensino-aprendizagem das escolas, limitando a potencialidade transformadora da educação. Sob a tutela de preceitos políticos conservadores e religiosos fundamentalistas, de base moral

\footnotetext{
${ }^{3}$ A íntegra da lei está no Anexo I.

${ }_{4} \mathrm{O}$ projeto de lei foi sancionado pelo deputado do mesmo partido, Ronaldo Medeiros (PMDB), vice-presidente da Assembleia Legislativa, que assinou a lei contrariado devido à circunstância de estar no exercício da Presidência da Assembleia, substituindo o presidente da instituição.
}

Revista Exitus, Santarém/PA, Vol. 8, No 1, p. 141 - 170, JAN/ABR 2018. 
reacionária, tal iniciativa legal procura impedir o exercício das liberdades, tendo como alvo principal a diversidade social, ética, cultural e, principalmente, de gênero, principal alvo dos ataques reacionários, como se observará adiante.

Do ponto de vista histórico, a lei aprovada em Alagoas se inspirou nas ideias do movimento autointitulado "Escola sem Partido", criado em 2003 a partir de uma iniciativa do procurador do Estado de São Paulo Miguel Nagib. O movimento diz representar pais e estudantes contrários à "doutrinação ideológica" que, segundo a opinião de seus seguidores, acontece nas salas de aula brasileiras. Para o movimento,

\begin{abstract}
A doutrinação política e ideológica em sala de aula ofende a liberdade de consciência do estudante; afronta o princípio da neutralidade política e ideológica do Estado; e ameaça o próprio regime democrático, na medida em que instrumentaliza o sistema de ensino com o objetivo de desequilibrar o jogo político em favor de um dos competidores.

Por outro lado, a exposição, em disciplina obrigatória, de conteúdos que possam estar em conflito com as convicções morais dos estudantes ou de seus pais, viola o art. 12 da Convenção Americana sobre Direitos Humanos, segundo o qual "os pais têm direito a que seus filhos recebam a educação religiosa e moral que esteja de acordo com suas próprias convicções".

(http://www.programaescolasempartido.org/saiba-mais)
\end{abstract}

Naquela época (em 2003), as propostas do movimento não eram conhecidas; no entanto, no ano de 2014 um encontro de Nagib com a família Bolsonaro mudou os rumos do movimento: o deputado estadual Flávio Bolsonaro (Partido Social Cristão - PSC) apresentou um projeto de lei elaborado por Nagib na Assembleia Estadual do Rio de Janeiro, e seu irmão, Carlos Bolsonaro, fez o mesmo na Câmara de Vereadores do Rio de Janeiro. Depois que Nagib disponibilizou os dois projetos no site do movimento, deputados e vereadores - na sua maioria ligados a bancadas religiosas, começaram a apoiar essas ideias, que passaram a reproduzir-se em diversas casas legislativas.

A partir desses projetos de lei, outros de cunho semelhante passaram a se multiplicar pelos demais entes federativos e no Congresso Nacional, 
sempre evocando os princípios da família tradicional contra a "doutrinação ideológica" e os desvios da "ideologia de gênero"5. Ao todo, quatro propostas tramitaram na Câmara dos Deputados nos últimos três anos: o Projeto de Lei (PL) 7.180/2014 proposto por Erivelton Santana (PSC/BA), que segundo sua ementa "Altera o art. $3^{\circ}$ da Lei no 9.394, de 20 de dezembro de 1996"; o PL 867/2015 de autoria do deputado Izalci Lucas Ferreira (PSDB/DF), que "Inclui, entre as diretrizes e bases da educação nacional, o Programa Escola sem Partido" (este projeto foi apensado ao PL 7.180/2014, em 26/03/2015); o PL 1.411/2015 de autoria de Rogério Marinho (PSDB/RN), que "Tipifica o crime de Assédio Ideológico e dá outras providências"; e o mais recente, O PL 193/2016, de autoria do senador Magno Malta (Partido da República - PR/ES), que "Inclui entre as diretrizes e bases da educação nacional, de que trata a Lei $n^{\circ}$ 9.394, de 20 de dezembro de 1996, o Programa Escola sem Partido".

Em nível estadual, onze propostas de lei foram encaminhadas para serem debatidas e aprovadas. Desse total, uma proposta foi aprovada em Alagoas (PL7. 800, em 05/05/2016), três foram arquivadas (PL 2.861/2014 em Goiás; PL 748/2015 no Paraná; e PL 121/2016 em Espírito Santo), e sete se encontram em processo de tramitação (PL 2.974/2014 no Rio de Janeiro; PL 190/2015 no Rio Grande do Sul; PL 3.101/2015 em São Paulo; PL 53/2015 no Distrito Federal; PL 273/2015 no Ceará; PL 102/2016 em Amazonas; e, PL 823/2016 em Pernambuco).

O projeto de Alagoas - único aprovado até o momento da conclusão deste artigo (janeiro de 2017) - ficou conhecido no estado como Programa Escola Livre. A lei, que foi promulgada pelo deputado Ronaldo Medeiros (PMDB), procura atuar na defesa a "neutralidade" ideológica, política e religiosa dos professores de escolas estaduais (ALAGOAS, 2016).

Setores significativos da sociedade civil e defensores do ensino público, gratuito e de qualidade socialmente referenciada acreditam que as

\footnotetext{
5 Outro termo que se popularizou nas discussões educacionais nos últimos anos, cuja origem e significado é igualmente bastante controverso.
} 
questões vinculadas à lei aprovada não representam apenas os reflexos de posições radicalizadas sobre a função e o papel da educação. Obviamente, não estão ligados unicamente aos conceitos de aprendizagem, liberdade e pluralidade de concepções pedagógicas. Para estes setores, tais questões significam riscos perceptíveis à democracia institucional, às práticas de solidariedade, tolerância e dignidade das pessoas - ou seja, ao arcabouço jurídico e político dos Direitos Humanos, consagrados pelas organizações internacionais e pelas legislações correlatas, dos quais o Brasil é signatário ${ }^{6}$. E esses riscos são consequências de um processo mais amplo: de ofensivas políticas e ideológicas articuladas pela direita liberal e conservadora brasileira, da qual fazem parte setores neofascistas ${ }^{7}$.

Na contramão de algumas análises apresentadas nos últimos tempos (SINGER, 2012), não parece plausível que estes movimentos de tendência neofascista tenham nascido unicamente estimulados pelo fortalecimento da direita política inconformada com os ganhos obtidos pelos segmentos populares durante a expansão econômica observada durante o segundo mandato da Presidência da República de Luiz Inácio Lula da Silva (20072010) e o primeiro mandato da Presidente Dilma Vana Rousseff (2011-2014). Ainda que esse fator seja relevante para o entendimento do fenômeno, para os autores deste artigo os reveses de natureza política estão imbricados no processo de deterioração dos fundamentos macroeconômicos do sistema capitalista, que em meio a mais uma das suas históricas crises cíclicas

\footnotetext{
6 Como a Convenção Americana de Direitos Humanos em 1992 e o reconhecimento da competência jurisdicional da Corte Interamericana de Direitos Humanos em 1998, conforme as informações de Koerner (2003).

7 Algumas características básicas definem o fascismo, como a defesa de um Estado autoritário, a eliminação dos adversários, o desrespeito aos direitos individuais, um nacionalismo exacerbado, a negação das diferenças. O neofascismo é um ressurgimento destas características na sociedade globalizada. Considera-se, neste ensaio, que tais práticas estão se tornando um fato crescente nos países ocidentais desde a agudização da crise do sistema capitalista. Tanto na década de 1920 como atualmente, as crises econômicas e os longos períodos de recessão favorecem esse sentimento de radicalização ideológica. No Brasil, esses traços de neofascismo estão cada dia mais evidentes e se fortalecendo ao longo dos últimos anos.
} 
com a inevitável diminuição das suas taxas de lucro, se reorganiza restringindo os direitos trabalhistas e sociais com vistas à recomposição do seu processo de acumulação e à garantia das suas margens lucratividade.

Não restam dúvidas de que a emergência do Programa Escola Livre no Estado de Alagoas faz parte de uma ação articulada de ataque aos direitos sociais e trabalhistas, com o propósito de assegurar os ganhos ilimitados ao sistema capitalista, no qual a esfera educacional é uma das frentes preferenciais de hegemonização das ideologias das classes dominantes. Esse ataque aos direitos sociais e trabalhistas têm seus fundamentos no processo de reordenamento do modo de produção capitalista que acontece mundialmente, e que colocam ao capitalismo e sua ideologia dominante (neoliberalismo) como sendo verdades absolutas e indiscutíveis. Lembre-se que no terreno econômico, o Brasil estava em completa integração com as mudanças geradas pela globalização econômica, subordinando sua política externa e interna aos imperativos do sistema do capital em sua etapa especulativa, com novos arranjos produtivos e tecnológicos eliminaram milhões de postos de trabalho, limitando a capacidade de intervenção estatal e comprometendo grande parte dos recursos públicos com o contingenciamento imposto pelo ajuste fiscal determinado pelos organismos internacionais de financiamento e pelas "forças de mercado".

Diante as considerações supracitadas, o presente artigo procura buscar respostas à seguinte questão norteadora: quais circunstâncias econômicas, políticas e ideológicas motivaram a aprovação da lei 7.800/2016, que institui o Programa Escola Livre no Estado de Alagoas?

Este artigo é resultado de uma análise pormenorizada e criteriosa dos fatos mencionados, com base em uma interpretação marxista da história, a partir do método do materialismo histórico e dialético (GRAMSCl, 1986; MARX, 2004, 2006, 2009). Por meio dele, é possível a compreensão global dos fenômenos investigados, a partir da premissa básica da existência dos conflitos de classe em formações sociais capitalistas, como é o caso da 
constituição social e econômica brasileira. Resultante da divisão da sociedade em classes antagônicas e inconciliáveis entende-se que o Estado, imparcial e neutro, esboçado pelos pensadores de matriz liberal, não passou de um engodo alimentado pela classe dominante burguesa com o intuito de manutenção da sua hegemonia.

Também são considerados como pressupostos iniciais que 0 entendimento contemporâneo da ação estatal decorre das reflexões carcerárias do pensador italiano Antônio Gramsci (1988, 2000, 2002, 2010) que lucidamente identificou no Estado seu sentido jurídico, político, econômico e ideológico sob a perspectiva ampliada, ou integral, conforme sua própria definição. Nesta compreensão, o Estado não representa unicamente os interesses das classes, mas é uma entidade em constante disputa, sujeito a inclinações parciais e arena própria dos conflitos existentes.

Com vistas a fundamentar as respostas à questão norteadora, o presente artigo procura realizar uma análise crítica da lei aprovada que instituiu o Programa Escola Livre, recentemente aprovada no Estado de Alagoas. Primeiramente serão abordadas a conjuntura econômica e política dos últimos anos, por entender-se que estes elementos acabam se entrelaçando e convergindo em diversos pontos.

Posteriormente, o artigo procura debater sobre os aspectos legais e políticos colocados em disputa, no que se refere especificamente ao Projeto Escola Livre aprovado no Estado de Alagoas, fazendo uma articulação com as variáveis ideológicas e estruturais subjacentes ao momento de crise da acumulação do capital, materializada nos aspectos políticos e legais mencionados. Paralelamente, procura-se contextualizar a realidade política, econômica e social alagoana em meio a essa conjuntura mais ampla. $\bigcirc$ artigo se encerra com a apresentação das Considerações Finais, retomando

\footnotetext{
8 Mas na ótica de Gramsci, nenhuma classe hegemônica detém o poder absoluto do Estado. Por isso, é obrigada em muitos momentos a recorrer ao apoio das demais classes em disputa, obrigando-se a contemplar parte dos interesses dos demais segmentos. Porém, não é improvável que o Estado assuma uma relativa independência dessas classes em conjunturas bastante específicas, mesmo representando contraditória e simultaneamente a síntese da classe hegemônica vigente.
} 
em grande medida as questões observadas ao longo do texto, com a pretensão de situar os nexos políticos e ideológicos dos argumentos desenvolvidos que ensejaram as interpretações em questão a respeito dos sentidos da lei 7.800/2016.

\section{A CONJUNTURA ECONÔMICA}

A crise do modo de produção do capital iniciada desde os anos de 1970 tem se agravado cotidianamente. Ela foi responsável pelo fim da experiência do Estado do Bem-estar Social (constatado apenas nos Estados Unidos da América e em alguns países da Europa Ocidental) e pelo fortalecimento da ideologia neoliberal em todo o mundo, sempre no sentido de diminuição e esvaziamento do caráter público do Estado e na subtração dos direitos trabalhistas e sociais.

$\mathrm{Na}$ verdade, estes foram os meios utilizados pelo capital para compensar a queda vigorosa das suas taxas de lucro, fenômeno cíclico inerente ao próprio sistema de acumulação, gerador de consequências catastróficas para a humanidade do decorrer dos séculos de sua primazia socioeconômica. À aguda retração econômica e restrição das margens de lucro do sistema, corresponderam ofensivas graduais às conquistas sociais obtidas nos tempos de abundância dos financistas, especuladores e industriais. Conforme a exposição de Lira (2016),

Desde a crise do capital iniciado no final da década de 1970, provocado, dentre outras razões, pela crise do dólar e pela dificuldade de rolagem da dívida pública dos Estados Unidos, que levou ao aumento internacional das taxas de juros, a geração do lucro passou a depender cada vez mais dos processos especulativos desencadeados pelo sistema financeiro nas Bolsas de Valores e na valorização dos títulos públicos. O capital desprendeu-se do trabalho e da produção de mercadorias enquanto componente essencial do sistema, assumindo um caráter claramente rentista, retirando recursos das áreas sociais para o pagamento dos seus encargos e lucros exorbitantes (LIRA, 2016, p.71).

A subtração dos recursos públicos que deveriam ser direcionadas à melhoria da qualidade de vida das pessoas mencionada acima se dá especialmente por meio do pagamento das dívidas externa e interna lque 
operam por dentro do aparelho estatal via autoridades monetárias, representantes legítimos dos interesses capitalistas) manipulando em benefício dos credores a política de juros e a política cambial, destruindo parques produtivos e extinguindo definitivamente as já escassas oportunidades de emprego outrora existentes.

Concomitante ao processo de reestruturação do capitalismo, temos no final do século XX ○ fracasso histórico da tentativa de "construir" 0 socialismo através do planejamento centralizado da economia e da estatização dos meios de produção, de cima para baixo, na União de Repúblicas Socialistas Soviéticas (URSS) e nas repúblicas democráticas surgidas no Leste Europeu. Segundo Aguiar,

O socialismo do século XX não conseguiu integrar o avanço social, planejamento econômico, com liberdade e democracia, e por isso ruiu na maioria dos países em que se implantou, depois de reproduzir muitas vezes as piores qualidades autoritárias das sociedades em que ele medrou (2006, p.16).

Tal fracasso revitalizou a hipótese de que o socialismo e seus modos de produção teriam que ser desenvolvidos sob a hegemonia do capitalismo. Para Singer (1998, p. 09), "O fracasso do socialismo realmente existente revelou que o socialismo sem aspas terá de ser construído pela livre iniciativa dos trabalhadores em competição e contraposição ao modo de produção capitalista, dentro da mesma formação social".

As fracassadas experiências socialistas permitiram a consolidação, em termos geopolíticos, do domínio do império americano, aplicando sua perversa lógica de agredir a natureza e a sociedade humana, em nome de sua ideologia, da mais-valia e da reprodução do capital. Segundo Hermida (2008),

Na sua configuração atual, percebe-se no imperialismo a existência de elementos pertencentes a sua fase clássica - tais como a ocupação territorial, os processos de acumulação capitalistas em escala mundial; domínio econômico e político dos países capitalistas desenvolvidos ou em vias de desenvolvimento; e a opressão dos povos subjugados pelo domínio do capital ao ponto de eliminar a questão nacional -, associados a novas características, tais como a superação de algumas questões territoriais - a mundialização do 
capital e o monopólio da informação (materiais) e o reforço de suas faces simbólicas e virtuais (imateriais). Esses novos elementos materiais e imateriais dotaram ao império de um poder supranacional mais incisivo, que lhe permite desenvolver um domínio global para cumprir incondicionalmente os interessas da classe dominante norte-americana (HERMIDA, 2008, p. 306).

A ideologia dominante que orientou esse processo de dominação social, política e econômica foi o neoliberalismo. Fazem parte da ideologia neoliberal a economia neoclássica, a racionalidade tecnocrática, o "fim da história" e sua contrapartida - a "morte do marxismo", a naturalização das relações coloniais de dominação, a fragmentação do conhecimento, a glorificação do individualismo e a exaltação das virtudes do mercado e da econômica, a superexploração dos recursos naturais e a consequente destruição ecológica do planeta. Esse amplo conjunto de características que caracterizam o atual momento social e conjuntural foram explicitadas nos textos de grandes cientistas sociais contemporâneos (BORÓN, 1998; FORRESTER, 2001; MÉSZÁROS, 2002; MILIBAND, 1995; e WALLERSTEIN, 2001). No contexto da "cruzada neoliberal" descrita por Moraes (1996), o que mais se destaca é sua vitória moral: palavras como desigualdade, desemprego, lucro, capital, mais-valia e desemprego passaram a ser aceitas nos discursos e diálogos de políticos e economistas, sem levar em consideração o peso e as consequências que cada uma dessas palavras representa.

Castelo (2013) considera, contudo, que o neoliberalismo "puro" de abertura indiscriminada aos investimentos estrangeiros, ao comércio internacional, que em suas premissas iniciais seria acompanhado de um amplo processo de privatização, retirada dos direitos trabalhistas e previdenciários, desmonte do Estado de Bem-estar Social, das estruturas sindicais etc. não ocorreu em nenhum lugar do mundo, tampouco no Brasil; em sua ótica, o que aconteceu na década de 1990 foi a implantação de uma variante da ideologia neoliberal, denominado por ele de socialliberalismo, arranjo político, econômico e ideológico adaptado ao caso brasileiro. 
Dentre os motivos para que as políticas de matriz neoliberal tenham sido aplicadas de maneira parcial, o autor menciona a resistência dos movimentos populares organizados, as divergências internas entre as próprias classes dominantes sobre o tratamento da questão social e o fracasso das medidas capitaneadas pelo Banco Mundial, Organização Mundial do Comércio e pelo Fundo Monetário Internacional na sustentação do crescimento econômico e na minimização da desigualdade social, ao contrário do que prometiam seus idealizadores.

Os teóricos do neoliberalismo apontam as deficiências da máquina pública na prestação dos serviços e sua apropriação por categorias profissionais como as causas da pobreza e do atraso. Nesse novo contexto, os servidores públicos, que se "apoderaram do Estado", devem então perder suas injustificadas vantagens conquistadas para permitir a redistribuição equitativa da riqueza construída socialmente. Com o inequívoco apoio da grande mídia, ocorre na realidade uma nova apropriação do Estado pelos agentes privados representantes dos interesses capitalistas em sua etapa oligopolizada e especulativa (CASTELO, 2013).

Diferenciações de intensidade e ajustes locais à parte, Mészáros (2011) enfatiza que, de modo geral, o neoliberalismo foi o mecanismo usado para minimização da crise do capital às voltas com sua histórica tendência de retração das taxas de lucro e de rentabilidade, dado a "margem historicamente restritiva das alternativas objetivamente factíveis do capital para deslocar e manejar suas contradições antagônicas" (p. 24). Tal estratagema, instável e precário, não solucionou as contradições próprias ao funcionamento do sistema, antes aprofundou-as penalizando ao limite o trabalho, base social da riqueza e da produção da mais-valia.

Para Mészáros (2011), a solução da crise cíclica implicaria na própria extinção do sistema, uma vez que as crises de acumulação são parte indissociável do mesmo; não podendo extinguir a crise sob pena da própria dissolução, resta a ele e aos seus agentes o adiamento permanente e autodestrutivo, prolongando todos os problemas criados com sua expansão 
e manutenção. Por esses motivos, qualquer tentativa de amenização das suas características fundamentais acarreta a ampliação das consequências negativas inerentes. Entretanto, seduzidos pelos representantes do sistema capitalista, no decorrer dos anos de experiência neoliberal, as recomendações dos organismos externos a serviço do capital foram seguidas, quase que sem mudanças aparentes, pela maioria dos sucessivos governos nacionais da América Latina. Os resultados são bastante conhecidos. A região mergulhou em um intenso processo de estagflação e teve sua economia drenada pelas dívidas contraídas a juros flutuantes (GOMES, 2014), gerando não apenas a década perdida de 1980, mas, fundamentalmente, um longo período de retrocesso dos direitos básicos e o desmonte do Estado em prol da estabilização monetária prometida.

Paradoxalmente, transformações sociais mais substantivas começam a ocorrer em alguns países da América Latina a partir da posse de governos progressistas (Argentina de Néstor Kirchner, 2003; Bolívia de Evo Morales, 2006; Chile de Michel Bachelet, 2006; Equador de Lucio Gutiérrez, 2003; Uruguai de Tabaré Vázquez, 2005; Venezuela de Hugo Chávez, 1999; e Brasil de Lula da Silva, 2003), dando início a uma fase de recomposição de alguns direitos básicos, em benefício da maioria da população.

Entretanto, a crise do sistema, aprofundada cotidianamente desde 2008 acabou por isolar as gestões que lograram a execução de políticas públicas voltadas ao atendimento das áreas sociais (a exemplo do acontecido em Argentina, Bolívia, Brasil, Uruguai e Venezuela), que foram tolhidas pelo novo avanço do sistema de acumulação. É por essas razões que os direitos trabalhistas e sociais são duramente atacados tanto no primeiro momento da implementação do neoliberalismo no Brasil na década de 1990 (FRIGOTTO, 2001) quanto na etapa histórica atual, principalmente a partir do momento em que o vice-presidente Michel Temer (PMDB) assume a Presidência da República após a aprovação de um processo de Impeachment contra a Presidente Dilma Rousseff (PT), em 2016. Este assunto será aprofundado na continuação deste artigo. 


\section{A CONJUNTURA POLÍTICA}

O êxito temporário das políticas anticíclicas aplicadas pelos países governados pelas forças políticas de perfil socialdemocrata permitiu ao trabalho - elemento central de produção de riquezas - manter alguns direitos consolidados nas legislações próprias de cada país. Isso só foi possível até o ano de 2008, enquanto a crise do sistema não se aprofundou de modo incontornável.

A experiência brasileira é emblemática. A coalizão de centroesquerda articulada sob a liderança do Partido dos Trabalhadores (PT) conduziu a Luiz Inácio Lula da Silva para a Presidência da República em 2003, e funcionou proporcionando ganhos relativos aos segmentos populares e médios no esquema de uma aliança instável na medida em que isto era funcional ao sistema, não ignorando as inúmeras contradições históricas identificadas por diversos analistas. Em dado momento, a continuidade desta aliança foi colocada em cheque, observando-se o brutal avanço das forças do mercado e dos seus representantes à direita, naquele surpreendente (mas não inédito) consórcio pragmático entre Poder Judiciário, mídia e parlamento, pondo fim à experiência petista no Governo Federal, após a aprovação de um processo de Impeachment contra a Presidente Dilma Rousseff (PT), em 2016.

O processo de Impeachment colocou ao Brasil perante uma nova e controversa realidade política nacional, tendo em vista que a Presidente Rousseff foi removida do seu cargo - mesmo tendo sido eleita democraticamente com mais de 54 milhões de votos. O Vice-Presidente Michel Temer (PMDB) se empossou através de um processo jurídicomidiático-parlamentar, orquestrado pelos setores mais conservadores e reacionários da sociedade brasileira. Essa estratégia política fez com que pairasse no ambiente a ideia de que mesmo sendo legal, o governo de Michel Temer pode ser caracterizado como ilegítimo.

Após o processo de Impeachment e sem qualquer demora, seguiramse um conjunto de iniciativas políticas que ampliaram o processo de retirada 
e de perda dos direitos sociais e trabalhistas - outrora definidos constitucionalmente, efetivado pelo principal partido de centro-direita lo PMDB), que a partir desse momento assume a direção dos ataques aos direitos sociais e trabalhistas, visivelmente tutelado pelos outros partidos políticos de direita e das forças do mercado, principalmente os Democratas (DEM), o Partido da Socialdemocracia Brasileira (PSDB), o Partido Trabalhista Brasileiro (PTB) e o Partido Popular Socialista (PPS).

$\mathrm{Na}$ verdade, o acirramento dos embates entre os segmentos ligados à educação pública e defensora do princípio da inclusão e os representantes dos segmentos mais conservadores e direitistas já havia sido evidenciado durante a realização da Conferencia Nacional de Educação de 2010, e prosseguiu durante toda a tramitação do Projeto de Lei do novo Plano Nacional de Educação entre 2010 e 2014, quando foi sancionado pelo Governo Federal. Os conflitos se exacerbaram pelos estados, por ocasião da criação ou adequação dos Planos Estaduais e Municipais de Educação, tendo como foco a temática da acusação tão alardeada pelos segmentos mais conservadores de que tais marcos legais estavam influenciados pela ideologia de gênero, que, na opinião dos integrantes do movimento Escola Sem Partido, provocaria a "desagregação e o fim das famílias".

A articulação dos setores políticos de direita e conservadores com características neofascistas, foi de fato se fortalecendo em torno ao Programa Escola Sem Partido, tendo seus respectivos desdobramentos nos embates dos planos subnacionais. Essa articulação política consegue apoios declarados das instituições católicas, das denominações evangélicas, de representantes do Ministério Público, de amplos setores da grande mídia, do empresariado e da maioria dos seus respectivos parlamentos. Embora extremamente atuantes, os grupos sociais e políticos defensores do princípio da inclusão, da não discriminação e da liberdade de culto das religiosidades de matriz africana foram sendo aos poucos isolados, e na essência dos termos legais das leis aprovadas, derrotados. 
Para os militantes do ensino público que acompanharam as discussões legislativas e as audiências públicas que trataram destes Planos e para os especialistas em política educacional, esse resultado não surpreendeu. Toda uma atmosfera de criminalização dos movimentos sociais e das camadas populares foi construída, manipulando crenças religiosas, preconceitos, princípios jurídicos e bandeiras morais, ignorando por completo o princípio da laicidade existente na Constituição Federal de 1988. Somado a estes discursos, o oportunismo eleitoral dos detentores de cargos públicos (principalmente vereadores e deputados estaduais e federais) consolidou a ofensiva direitista, reacionária e conservadora.

A esse respeito, Gramsci argumenta que

[...] a supremacia de um grupo social se manifesta de duas maneiras, como 'domínio' e como 'direção intelectual e moral'. Um grupo social é dominante dos grupos adversários que tende a 'liquidar' ou submeter mesmo que com a força armada e é dirigente dos grupos afins e aliados. Um grupo social pode e deve ser dirigente já antes de conquistar o poder governativo (esta é uma das condições principais para a própria conquista do poder); depois, quando exercita 0 poder e na medida em que o mantém fortemente em suas mãos, toma-se dominante, mas deve continuar sendo 'dirigente' (GRAMSCl, 2010, p. 385).

A categoria de hegemonia gamsciana exposta acima é, na avaliação dos autores deste artigo, extremamente importante para a caracterização, no plano da batalha das ideias, daqueles conflitos potencializados pelo modo de produção entre as classes sociais na formação social capitalista. Os segmentos que representam as forças em disputa alinham-se no cenário montado a partir das contradições alimentadas e perpetuadas pelo próprio sistema de acumulação. A díade esquerda e direita, consagrada pelas Ciências Sociais, é um esquema discursivo plenamente oportuno e adequado para a explicitação dos posicionamentos adotados pelas partes contenciosas que fazem parte da disputa.

Estes elementos estão intrinsecamente vinculados aos debates sobre a natureza ideológica dos embates travados na sociedade contemporânea, uma vez que é natureza da construção ideológica a negação da existência 
dos interesses ocultos que estão na base da disseminação dos valores éticos e morais que governam determinada formação social concreta, como relembra Chauí (2000). As classes dominantes, historicamente, procuram transformar as ideias hegemônicas de cada tempo em verdades inquestionáveis e eternizadas, encobrindo os conflitos de classes existentes do qual são originadas, condição sine qua non deste domínio.

Umas das consequências desse construto ideológico que tenta a todo custo negar as contradições das classes em conflito - e negar mesmo o próprio conflito - é que as crises políticas, econômicas e sociais se tornam fatores recorrentes nas sociedades divididas em classes, no qual o Brasil evidentemente não está imune.

Os estudos desenvolvidos neste artigo apontam para a ideia de que reside especificamente no sistema educacional em geral, e nos debates vinculados ao Movimento Escola Sem partido em particular, um destes pontos de tensão e disputa político-ideológica. Expresso nas disputas em torno da formulação do novo Plano Nacional de Educação (PNE, de 2014) e dos planos de educação subnacionais, o novo capítulo do acirrado embate entre os segmentos de classe opostos e inconciliáveis se manifestou em um dos menores estados da República Federativa do Brasil, novamente no terreno jurídico. Desse embate trata o item seguinte.

\section{A APROVAÇÃO DA LEI DA "ESCOLA LIVRE" E O ASPECTO LEGAL}

Antes da promulgação da Lei n 7.800 em maio de 2016, uma série de acontecimentos colaboraram para a criação do clima favorável a sua aprovação pelos deputados estaduais em Alagoas. De fato, os embates políticos e jurídicos sobre as concepções educacionais em Alagoas, iniciaram no final do ano de 2014, quando vieram a público as discussões em torno da chamada ideologia do gênero que supostamente estaria incutida nos Planos Municipais de Educação em processo de construção ou revisão nos municípios. A discussão sobre esses planos, até então restrito a 
segmentos da comunidade educacional sem um maior interesse da opinião pública, ocupou repentinamente as manchetes dos noticiários diários.

Conforme as entrevistas e denúncias dos integrantes da Escola Livre, a ideologia de gênero fazia parte de um movimento pós-moderno de negação das diferenças físicas e psicológicas entre os sexos, descontruindo os pilares fundamentais da família heterossexual tradicional e estimulava criminosamente a iniciação (homo)sexual das crianças. Exibiam, como pretensa comprovação, cartilhas de orientação sexual distribuídas pelo Ministério da Educação (MEC) e pelas prefeituras em vários pontos do país. Ao MEC, inclusive, cabia a responsabilidade principal pela tentativa de distribuição de um material didático destinado às escolas de Educação Básica apelidado de kit gay, em alusão aos objetivos não declarados do ministério de estímulo à homossexualidade e à perversão sexual. Alguns dos slogans do Movimento Escola sem Partido coordenado pelo procurador Miguel Nagib eram justamente "Deixem nossas crianças em paz", "Deixem as crianças serem crianças" e até mesmo "País contra a pedofilia".

As discussões sobre os Planos Municipais de Educação (PME's) do Estado de Alagoas passaram a fazer parte do cotidiano das reuniões das Secretarias de Educação, escolas, conselhos e entidades de educação, igrejas, associações de bairro e das Câmaras de Vereadores. Quando o debate sobre o PME da capital Maceió foi objeto de audiência pública na Câmara de Vereadores, as entidades e instituições educacionais se posicionaram contrariamente aos posicionamentos do Movimento Escola Livre, que liderava as diversas instituições religiosas em uma investida direta contra os segmentos sociais historicamente excluídos.

$\mathrm{Na}$ primeira audiência pública acontecida sobre o tema?, praticamente não havia espaço para debates com base em um mínimo de

9 Do segmento educacional, participaram das audiências públicas entidades representantes do Fórum Estadual Permanente de Educação do Estado de Alagoas (FEPEAL), Secretaria estadual e municipal da educação, Conselho Estadual de Educação (CEE), Conselho Municipal de Educação de Maceió, Universidade Federal de Alagoas (UFAL), Universidade Estadual de Alagoas, Sindicato dos Trabalhadores da Educação de 
razoabilidade. Enquanto a plenária e as galerias eram tomadas majoritariamente pelos grupos religiosos que prestigiavam e aplaudiam efusivamente os oradores que brandiam contra a ideologia do gênero em defesa da família, outras centenas de pessoas acompanhavam as sessões na praça central em frente ao parlamento, com transmissão ao vivo em telões improvisados. Um trio elétrico, carros de som e dezenas de faixas organizadas pelas denominações religiosas cristãs completavam a cena. Os educadores convidados para explicar as metas e diretrizes do Plano Municipal de Educação (PME) em discussão mal foram ouvidos pelo público majoritário, indignados, pois já haviam se posicionado contra a ideologia de gênero.

Na segunda audiência, os segmentos sociais defensores do ensino público conseguiram se organizar antecipadamente e ocuparam a maior parte dos espaços internos das galerias e das plenárias. Evidentemente, isso não impediu que líderes religiosos, vereadores, deputados estaduais e um deputado federal fizessem discursos inflamados contra os supostos objetivos do PME de destruição das famílias e da infância. Quando O PME foi sancionado pelo prefeito de Maceió, todos os vetos sugeridos pelo Movimento Escola Livre que foram transformados em ementas parlamentares foram aceitos.

O mesmo clima de radicalização se repetiu nos demais municípios e na Assembleia Legislativa por ocasião da apreciação do Plano Estadual de Educação. De igual modo, o governador Renan Filho (PMDB) acatou as imposições dos conservadores e vetou artigos do Plano Estadual de Educação (PEE) considerados prejudicais à família tradicional, bem como apôs outros vetos nos itens relativos a financiamento, acompanhamento da sociedade civil e muitas outras metas apresentadas pelos segmentos educacionais.

Alagoas (SINTEAL) Instituto Federal de Alagoas (IFAL), Campanha Nacional pelo Direito a Educação em Alagoas, dentre outras. 
A apresentação do projeto de lei do Programa Escola Livre originou-se desse processo de radicalização política e ideológica, sumariamente exposto acima. Vetado o projeto de lei pelo governador Renan Filho (PMDB), os deputados estaduais derrubaram o veto e promulgaram a referida Lei em maio de 2016. Assim que a lei $n^{\circ} 7.800 / 2016$ foi aprovada, o governador do Estado de Alagoas reiterou a inconstitucionalidade da Lei, afirmando que a lei significava uma ingerência na política educacional do Estado, gerando dispêndio pecuniário e interferindo em matéria de iniciativa privativa do chefe do Poder Executivo.

Em seguida, a Confederação Nacional dos Trabalhadores em Estabelecimentos de Ensino (CONTEE) foi a primeira entidade a propor uma Ação Direta de Inconstitucionalidade ( $n^{\circ}$ 5537), questionando a Lei do Programa Escola Livre aprovada em Alagoas. Mesmo não reconhecendo a legitimidade da CONTEE para a propositura da ação, a Advocacia Geral da União (AGU) teceu importantes considerações sobre a constitucionalidade da lei.

Em resposta encaminhada ao Supremo Tribunal Federal, a Advocacia Geral da União (AGU) argumentou que:

O artigo 22, inciso XXIV, da Constituição, ao conferir à União a competência para dispor sobre diretrizes e bases da educação nacional, nada mais faz do que explicitar a competência do legislador federal para definir as normas gerais sobre educação que, no caso, foram veiculadas pelo diploma legal $n^{\circ}$ 9.394/96 (Lei de Diretrizes e Bases da Educação Nacional). A mencionada Lei federal $n^{\circ}$ 9.394/96, em seu artigo $3^{\circ}$, estabelece os princípios que devem nortear o ensino no Brasil [...].

O texto passou então a enumerar os ditos princípios:

Art. $3^{\circ} \mathrm{O}$ ensino será ministrado com base nos seguintes princípios:

I - igualdade de condições para o acesso e permanência na escola;

II - liberdade de aprender, ensinar, pesquisar e divulgar a cultura, 0 pensamento, a arte e o saber;

III - pluralismo de ideias e de concepções pedagógicas; IV - respeito à liberdade e apreço à tolerância;

$\checkmark$ - coexistência de instituições públicas e privadas de ensino; VI gratuidade do ensino público em estabelecimentos oficiais;

VII - valorização do profissional da educação escolar; 
VIII - gestão democrática do ensino público, na forma desta lei e da legislação dos sistemas de ensino;

IX - garantia de padrão de qualidade;

$X$ - valorização da experiência extraescolar;

XI - vinculação entre a educação escolar, o trabalho e as práticas sociais:

XII - consideração com a diversidade étnico-racial.

Por sua vez, estes mesmos princípios seguem basicamente o texto proposto na Constituição Federal de 1988 (CF/88), que em seu Art. 206 define que o ensino será ministrado com base nos princípios de "pluralismo de ideias e de concepções pedagógicas". Este é um dos artigos mencionados pelo então ministro da Educação Aloizio Mercadante em nota pública, onde ele afirma que "a lei de Alagoas contraria os princípios legais, políticos e pedagógicos que orientam a política educacional brasileira", complementando que "tal pluralidade efetiva-se somente mediante o reconhecimento da diversidade do pensamento, dos diferentes saberes e práticas".

Nos anos posteriores à promulgação da CF/88 e da LDBEN de 1996, um conjunto importante de aportes legais foi sendo construído na área educacional em relação à temática da diversidade. É o que destacou Fleuri em 2003, relembrando que:

Desde o lançamento dos Parâmetros Curriculares Nacionais, que elegeram a pluralidade cultural como um dos temas transversais (Brasil, Ministério da Educação, 1997), o reconhecimento da multiculturalidade e a perspectiva intercultural ganharam grande relevância social e educacional com o desenvolvimento do Referencial Curricular Nacional para as Escolas Indígenas, com as políticas afirmativas das minorias étnicas, com as diversas propostas de inclusão de pessoas portadoras de necessidades especiais na escola regular, com a ampliação e reconhecimento dos movimentos de gênero, com a valorização das culturas infantis e dos movimentos de pessoas de terceira idade nos diferentes processos educativos e sociais (2003, p.16).

Em resposta, ao posicionamento da AGU, a Assembleia Legislativa de Alagoas

[...] aduziu que a lei em questão tenciona apenas vedar a prática, em todo o Estado, de doutrinação política e ideológica e quaisquer condutas, por parte do corpo docente ou da administração escolar, que imponham ou induzam aos alunos, de modo parcial, opiniões 
político partidárias, religiosas e/ou filosóficas. Afirmou, ainda, que o Estado possuiria competência concorrente para legislar sobre educação. Com essas considerações, posicionou-se pela constitucionalidade da norma legal sob invectiva.

O Ministério Público Federal também se manifestou veementemente contra a lei alagoana. Argumentou que a lei revela o inconformismo com a vitória das diversas lutas emancipatórias durante o processo constituinte e com a formatação de uma sociedade aberta a múltiplas, as diferentes visões de mundo e com o fato de a escola "ser um lugar estratégico para a emancipação política e para o fim das ideologias sexistas". O MPF adverte que o PL subverte a atual ordem constitucional enumerando que o mesmo:

(I) Confunde a educação escolar com aquela que é fornecida pelos pais, e, com isso, os espaços público e privado;

(II) Impede o pluralismo de ideias e de concepções pedagógicas (art. 206, III);

(III) Nega a liberdade de cátedra e a possibilidade ampla de aprendizagem (art. 206, II);

(IV) Contraria o princípio da laicidade do Estado, porque permite, no âmbito da escola, espaço público na concepção constitucional, a prevalência de visões morais/religiosas particulares.

O Conselho Universitário da Universidade Federal de Alagoas (CONSUNI/UFAL) também aprovou moção de repúdio contra a lei aprovada pela Assembleia. Na nota, também mencionou as manifestações públicas das instituições acadêmicas e da Pró-Reitoria de Graduação da UFAL, do Curso de História (ICHCA/UFAL), do Centro de Educação (CEDU/UFAL), do Instituto de Ciências Sociais (ICS/UFAL), assim como da Universidade Estadual de Alagoas (UNEAL), da Associação dos Docentes da UFAL (ADUFAL), DO Sindicato dos Trabalhadores da UFAL (SINTUFAL), do sindicato dos Trabalhadores da Educação em Alagoas (SINTEAL), do Sindicato dos Professores de Alagoas (SINPRO), do Conselho Municipal de Educação de Maceió (COMED), e do Conselho Regional de Serviço Social de Alagoas (CRESS/AL). Os posicionamentos contrários da Secretaria de Educação de Alagoas e do Ministério da Educação também foram mencionados na nota do CONSUNI. 
Ao conjunto dos educadores, uma das questões mais surpreendentes é que todo o avanço construído socialmente em termos de respeito à dignidade e diferença das pessoas parecia algo consolidado em termos gerais e plenamente incorporado pela maioria da sociedade. Não foi por acaso que a Resolução $n^{\circ} 1$ do Conselho Nacional de Educação (CNE), aprovada em 30 de maio de 2012, publicada no dia 31, que estabeleceu as Diretrizes Nacionais para a Educação em Direitos Humanos, logo em seu art. $3^{\circ}$, inc. II, define como um dos seus princípios o "reconhecimento e valorização das diferenças e das diversidades" (BRASIL, 2012). É o que enfatiza Koerner (2003), quando relembra que, "do ponto de vista do processo político, a indivisibilidade dos direitos humanos" [...] passou a compor uma agenda mais ampla levando em consideração "as demandas de grupos minoritários, com características particulares ou em situação de risco" (2003, p. 151).

Se até então, historicamente, os direitos civis e políticos estavam razoavelmente expressos no arcabouço legal existente, outras reivindicações e necessidades passaram a ser incorporadas, mesmo em graus de prioridades diferentes. E isto, na opinião de Kretschmann (2008), que ao analisar a diversidade étnica e cultural civilizacional no tocante as relações internacionais, acredita que a diversidade se torna um ponto positivo, na medida em que "a diversidade, antes de constituir um fator inibidor da universalidade [...], se constitui um valor agregador para a eficácia dos direitos (2008, p. 13)".

\section{COSIDERAÇÕES FINAIS}

A inconstitucionalidade da lei da Escola Livre, de acordo com os argumentos enumerados acima, é um fato que pode ser amplamente demonstrado. Caberá naturalmente ao Supremo Tribunal Federal a decisão final sobre o tema. Não obstante, o provável teor inconstitucional da lei não minimiza a importância política e ideológica de proposições desta natureza, que devido a sua origem preconceituosa, aos objetivos patentes de 
supressão das liberdades democráticas e de existência de formas de sociabilidade diversas, simbolizam a fragilidade dos avanços políticos e de inclusão social observados em um passado recente.

Notoriamente, existem campos de disputa política e ideológica em campo; a primeira, defensora do princípio da inclusão dos segmentos sociais que foram oprimidos e (in)visibilizados historicamente e a segunda, defensora da seletividade dos valores centrais que considera serem os apropriados à uma sociedade, demarcados por uma concepção reduzida das dinâmicas que orientam a convivência coletiva.

No caso do estado de Alagoas, também é importante mencionar a existência de fortes traços de prática coronelista e violência política, que convivem historicamente com um elevado índice de desigualdade social e concentração de riquezas. Aproveitando-se de tal realidade, as graças dirigentes monopolizam o poder econômico e político, mesmo nos momentos históricos de expansão das ações sociais e de inclusão das camadas populares, como aconteceu na gestão Lula da Silva (2003-2006; 2007-2010) e no primeiro governo de Dilma Rousseff (2011-2014).

Outro aspecto importante, implícito no corpo da lei $n^{\circ} 7.800 / 2016$, diz respeito a tentativa de homogeneização dos sujeitos educacionais, negando as diferenças existentes no tecido social. Candau (2008), com base em Pierucci (1999) e Santos (2003), já havia constatado que "o centro de interesse do debate sobre o respeito aos direitos humanos se deslocou", colocando-se "muito mais em evidência o tema da diferença", na relação direta com a questão da igualdade (CANDAU, 2008, p.45). Também cabe ressaltar a tentativa de monitorar o trabalho docente, esvaziando-o de conteúdos e de metodologias que promovam o espírito crítico dos alunos.

Na mesma linha, Lima (2009) explica que o conceito de igualdade evocados pelas concepções de democracia burguesa em algum momento se confrontam com as categorias da diferença e da equidade, estas mais inter-relacionadas do que a percepção de que todos seriam simplesmente iguais diante da lei. A contradição reside na questão da equidade como 
princípio formal, que em tese garante o respeito às diferenças, ao contrário mesmo do conceito da igualdade, tendente ao desconhecimento das particularidades e singularidades das pessoas.

Para Fleuri (2001, p. 68), essa homogeneização tenta diluir identidades e apagar as marcas das outras culturas que não estão de acordo com o padrão de dominação estabelecido, preocupação apontada antes por Aranha (1994). Ora, como falar em respeito às diferenças se o documento legal pretende a supressão destas subjetividades?

Em outra perspectiva, também é notório que por mais que a pluralidade da sociedade brasileira seja uma característica oficialmente divulgada e comemorada pelos entes governamentais e pela grande mídia, o majoritário apoio de diversos setores destas instituições às iniciativas legais como a que estamos discutindo aqui, revela a hipocrisia das peças publicitárias e a realidade efetiva dos conflitos de classe no país.

Em face das questões expostas, é preciso urgentemente radicalizar os espaços de convivência democrática no campo institucional e denunciar abertamente as tentativas de apartheid social que as classes dominantes pretendem impor aos segmentos excluídos, criando nesse processo, instrumentos alternativos de disputa da hegemonia da sociedade. A educação, em tal situação, é um desses campos de conflito, no qual todos desempenham papel fundamental na eliminação dos preconceitos e na igualização dos direitos.

Pode-se concluir que os conceitos de educação, igualdade, liberdade e política evocados no texto da lei, evidenciam que o mesmo foi elaborado a partir de concepções ideológicas e de democracia liberais e conservadoras. Essas concepções se confrontam com as contradições, pluralidade e diversidade reais que caracterizam a sociedade brasileira.

\section{REFERÊNCIAS}

ALAGOAS. Lei n 7.800, de 05 de maio de 2016. Lei da Escola Livre. Maceió: Imprensa Oficial, 2016.

ARANHA, M. L. de A. Filosofando. 2 ed. São Paulo: Moderna, 1994. 
BORÓN, A. EPÍLOGO: una teoria social para el siglo XXI. Trabalho apresentado no XIV Congreso Mundial de la Asociación Internacional de Sociologia. Montreal, Canadá: 1998. Disponível em http://campus.clacso.edu.ar Acesso em: 25/01/2016.

BRASIL. AÇÃO DIRETA DE INCONSTITUCIONALIDADE n 5537. Advocacia Geral da União. Braślia: 2016.

BRASIL. Constituição da República Federativa do Brasil. Atualizada e ampliada. São Paulo: Saraiva, 2013.

BRASIL. Ministério da Educação. Conselho Nacional de Educação. Estabelece Diretrizes Nacionais para a Educação em Direitos Humanos. Resolução CNE/CP 1/2012. Diário Oficial da União, Brasília, 31 de maio de 2012 - Seção 1 - p. 48.

BRASIL. Lei de Diretrizes e Bases da Educação Nacional. Lei n 9.394, de 20.12.1996.

BRASIL. Ministério da Educação. Aviso n 111/2016-GM/MEC. Brasília: 09 de maio de 2016.

BRASIL. Ministério Público Federal. Procuradoria Federal dos Direitos do Cidadão. Nota Técnica 01/2016 PFDC. Brasília, 21 de julho de 2016.

CANDAU, V. M. Direitos humanos, educação e interculturalidade: as tensões entre igualdade e diferença. Revista Brasileira de Educação v. 13 n. 37 jan./abr. 2008.

CASTELO, R. O social-liberalismo: auge e crise da supremacia burguesa na era neoliberal. São Paulo: Expressão Popular, 2013.

CHAUÍ, M. S. O que é ideologia. São Paulo: Brasiliense, 2000.

FORRESTER, V. Uma estranha ditadura. São Paulo: Editora da UNESP, 2001.

FLEURI, R. M. Multiculturalismo e interculturalismo nos processos educacionais. In: CANDAU, V. (Org). Ensinar e aprender: sujeitos, saberes e pesquisa. $2^{a}$ ed. Rio de Janeiro: DP\&A, 2001.

FLEURI, R. M. Intercultura e educação. Revista Brasileira de Educação. Maio/Jun/Jul/Ago. $2003 n^{\circ} 23$.

FRIGOTTO, G. Educação e Trabalho: bases para debater a Educação Profissional Emancipadora. PERSPECTIVA, Florianópolis, v.19, n.1, p.71-87, jan. /jun. 2001.

GOMES, J. M. Fundos de pensão, capital estatal e neodesenvolvimentismo. Revista de Políticas Públicas. São Luís, Número Especial, p. 155-159, julho de 2014.

GRAMSCl, A. Concepção dialética da história. $6^{a}$ ed. Rio de Janeiro: Civilização Brasileira, 1986. 
GRAMSCl, A. Os intelectuais e a organização da cultura. 6. ed. Trad. de Carlos Nelson Coutinho. Rio de Janeiro: Civilização Brasileira, 1988. (Coleção perspectiva do homem, v.48.).

GRAMSCl, A. Cadernos do Cárcere. V. 3. Maquiavel. Notas sobre o Estado e a política. Rio de Janeiro: Civilização Brasileira, 2000.

GRAMSCl, A. Os intelectuais, o princípio educativo, jornalismo. 2. ed. Trad. Carlos Nelson Coutinho. Rio de Janeiro: Civilização Brasileira, 2001. (Cadernos do Cárcere, v.2.).

GRAMSCl, A. Maquiavel: notas sobre o Estado e a política. 2. ed. Trad. Carlos Nelson Coutinho et al. Rio de Janeiro: Civilização Brasileira, 2002. (Cadernos do Cárcere, v.3.).

GRAMSCl, A. Cadernos do cárcere. Volume 1: Introdução ao estudo da filosofia. A filosofia de Benedetto Croce. Rio de Janeiro: Civilização Brasileira, 2010.

HERMIDA, J. F. Socialismo e Ciência da História em Karl Marx. In: ALMEIDA FILHO, A.; BARROS, V. S. de C. Novo manual de Ciência Política. São Paulo: Malheiros Editores, 2008.

KOERNER, A. O papel dos direitos humanos na política democrática: uma análise preliminar. Revista Brasileira de Ciências Sociais. Vol. $18 n^{\circ} 53$, outubro/2003.

KRETSCHMANN, Â. Choque entre civilizações ou culturas? Faz diferença para a compreensão dos Direitos Humanos? Revista Culturas Jurídicas. V. $3 \mathrm{n}^{\circ} 1$. Jan/Junh. 2008. Disponível em www.culturasjuridicas.com.br

LIMA, L. F. Relação entre a cidadania e o direito à igualdade: a face positiva e a negativa. Diálogo e interação. Volume 1 (2009) - ISSN 2175-3687. Disponível em http://www.faccrei.edu.br/dialogoeinteracao. Acessado em 15 de agosto de 2016.

LIRA, J. S. O neoliberalismo na educação pública alagoana durante o governo Teotonio Vilela (2007 a 2014). Tese (Doutorado em Educação). Universidade Federal da Paraíba/PB, 2016.

MARX, K.; ENGELS, F. Manifesto do partido comunista. São Paulo: Martin Claret, 2004.

MARX, K. Manuscritos econômico-filosóficos. São Paulo: Marin Claret, 2006.

MARX, K.; ENGELS, F. A ideologia alemã. São Paulo: Expressão Popular, 2009.

MÉSZÁROS, I. Estrutura social e formas de consciência II: a dialética da estrutura e da história. São Paulo: Boitempo, 2011.

MÉSZÁROS, I. Para além do capital: rumo a uma teoria da transição. São Paulo: Boitempo Editorial, 2002

MILIBAND, R. A plausibilidade do socialismo. In: SADER, E. (org.). O mundo depois da queda. São Paulo: Paz e Terra, 1995. 
MORAES, R. C. de. A democracia malcomportada: a teoria política do neoliberalismo econômico. In: Revista Universidade e Sociedade, ano VI, n. 11, junho de 1996. Pp. 121-129.

MOÇÃO DE REPÚDIO À APROVAÇÃO DO PROJETO DE LEI "ESCOLA LIVRE" EM ALAGOAS. Universidade Federal de Alagoas. Maceió: 09 de maio de 2016.

PIERUCCI, A. F. Ciladas da diferença. São Paulo: Editora 34, 1999.

SANTOS, B. de S. (Org.). Reconhecer para libertar: os caminhos do cosmopolitismo multicultural. Rio de Janeiro: Civilização Brasileira, 2003.

SINGER, A. Os sentidos do lulismo: reforma gradual e pacto conservador. São Paulo: Companhia das Letras, 2012.

SINGER, P. Uma utopia militante: repensando o socialismo. $2^{a}$. Ed. PetrópolisRJ: Editora Vozes, 1998.

WALLERSTEIN, I. Para abrir las Ciencias Sociales. Informe de la Comisión Gulbenkian, para la estructuración de las Ciencias Sociales. México: Siglo XXI, 2001.

Recebido em: Fevereiro de 2017

Aprovado em: Agosto de 2017 


\section{ANEXO I \\ LEI No 7.800, DE 05 DE MAIO DE 2016. INSTITUI, NO ÂMBITO DO SISTEMA ESTADUAL DE ENSINO, O PROGRAMA "ESCOLA LIVRE"}

Art. $1^{\circ}$ - Fica criado, no âmbito do sistema estadual de ensino, o Programa "Escola Livre", atendendo os seguintes princípios:

I - neutralidade política, ideológica e religiosa do Estado;

II - pluralismo de ideias no âmbito acadêmico;

III - liberdade de aprender, como projeção específica, no campo da educação, da liberdade de consciência;

IV - liberdade de crença;

$\checkmark$ - reconhecimento da vulnerabilidade do educando como parte mais fraca na relação de aprendizado;

$\mathrm{VI}$ - educação e informação do estudante quanto aos direitos compreendidos em sua liberdade de consciência e de crença;

$\mathrm{VII}$ - direito dos pais a que seus filhos menores recebam a educação moral livre de doutrinação política, religiosa ou ideológica; Art. $2^{\circ}$ - São vedadas, em sala de aula, no âmbito do ensino regular no Estado de Alagoas, a prática de doutrinação política e ideológica, bem como quaisquer outras condutas por parte do corpo docente ou da administração escolar que imponham ou induzam aos alunos opiniões político-partidárias, religiosa ou filosófica. $\S 1^{\circ}$ Tratando-se de disciplina facultativa em que sejam veiculados os conteúdos referidos na parte final do caput deste artigo, a frequência dos estudantes dependerá de prévia e expressa autorização dos seus pais ou responsáveis.

$\S 2^{\circ}$ As escolas confessionais, cujas práticas educativas sejam orientadas por concepções, princípios e valores morais, religiosos ou ideológicos, deverão constar expressamente no contrato de prestação de serviços educacionais, documento este que será imprescindível para o ato da matrícula, sendo a assinatura deste a autorização expressa dos pais ou responsáveis pelo aluno para veiculação de conteúdos identificados como os referidos princípios, valores e concepções.

$\S 3^{\circ}$ - Para os fins do disposto nos Arts. $1^{\circ}$ e $2^{\circ}$ deste artigo, as escolas confessionais deverão apresentar e entregar aos pais ou responsáveis pelos estudantes, material informativo que possibilite o conhecimento dos temas ministrados e dos enfoques adotados.

Art. $3^{\circ}$ - No exercício de suas funções, o professor:

I - não abusará da inexperiência, da falta de conhecimento ou da imaturidade dos alunos, com o objetivo de cooptá-los para qualquer tipo de corrente específica de religião, ideologia ou político-partidária; 
II - não favorecerá nem prejudicará os alunos em razão de suas convicções políticas, ideológicas, morais ou religiosas, ou da falta delas;

III - não fará propaganda religiosa, ideológica ou político-partidária em sala de aula nem incitará seus alunos a participar de manifestações, atos públicos ou passeatas;

IV - ao tratar de questões políticas, sócio-culturais e econômicas, apresentará aos alunos, de forma justa, com a mesma profundidade e seriedade, as principais versões, teorias, opiniões e perspectivas das várias concorrentes a respeito, concordando ou não com elas;

$\checkmark$ - salvo nas escolas confessionais, deverá abster-se de introduzir, em disciplina ou atividade obrigatória, conteúdos que possam estar em conflito com os princípios desta lei.

Art. $4^{\circ}$ - As escolas deverão educar e informar os alunos matriculados no ensino fundamental e no ensino médio sobre os direitos que decorrem da liberdade de consciência e de crença asseguradas pela Constituição Federal, especialmente sobre o disposto no Art. $3^{\circ}$ desta Lei.

Art. 5- A Secretaria Estadual de Educação promoverá a realização de cursos de ética do magistério para os professores da rede pública, abertos à comunidade escolar, a fim de informar e conscientizar os educadores, os estudantes e seus pais ou responsáveis, sobre os limites éticos e jurídicos da atividade docente, especialmente no que se refere aos princípios referidos no Art. $1^{\circ}$ desta Lei.

Art. $6^{\circ}$ - Cabe a Secretaria Estadual de Educação de Alagoas e ao Conselho Estadual de Educação de Alagoas fiscalizar o exato cumprimento desta lei.

Art. $7^{\circ}$ - Os servidores públicos que transgredirem o disposto nesta Lei estarão sujeitos a sanções e as penalidades previstas no Código de Ética Funcional dos Servidores Públicos e no Regime Jurídico Único dos Servidores Públicos Civil do Estado de Alagoas.

Art. $8^{\circ}$ - Esta Lei entrará em vigor na data de sua publicação.

Art. $9^{\circ}$ - Revogam-se todas as disposições em contrário.

GABINETE DA PRESIDÊNCIA DA ASSEMBLÉIA LEGISLATIVA ESTADUAL, em Maceió, 05 de maio de 2016.

Dep. RONALDO MEDEIROS Vice-Presidente, no exercício da Presidência. PUBLICADO NA SECRETARIA DA ASSEMBLÉIA LEGISLATIVA ESTADUAL, em Maceió, 05 de maio de 2016. 